\title{
Genetic Characterization of Gainj- and Kalam-Speaking Peoples of Papua New Guinea
}

\author{
JEFFREY C. LONG, JAMMIGUMPULA M. NAIDU, HARVEY W. \\ MOHRENWEISER, HENRY GERSHOWITZ, PATRICIA L. JOHNSON, \\ JAMES W. WOOD, AND PETER E. SMOUSE \\ Department of Human Genetics (J.C.L., J.M.N., H.W.M., H.G., J.W.W. \\ P.E.S.) and Department of Anthropology (P.L.J.), University of Michigan, \\ Ann Arbor, Michigan 48109; Department of Sociology and Anthropology, \\ College of Wooster, Wooster, Ohio 44619 (P.L.J.)
}

\section{KEY WORDS Genetic polymorphism, Heterozygosity}

\begin{abstract}
The research presented focuses on genetic variation in the Gainj- and Kalam-speaking peoples of highland Papua New Guinea. The primary data are typings at 51 genetic loci observed on 600 individuals who reside in 21 census units, called parishes. These data are augmented by cultural and demographic information that has also been collected.

Parish sizes are small, ranging from 20 to about 200 individuals. Direct Western contact with these people has been occuring only for the past three decades. Although Westernization is currently increasing, we find that much of the traditional settlement pattern and mate exchange system is preserved. There are segregating variants at 27 loci. Four rare variants are initially described: NP 4-Kalam, ADA 6-Kalam, PEPA 3-Kalam, and FUM 2-Kalam. We find evidence for a new Gm haplotype, a; - that is recessive to all other $\mathrm{Gm}$ haplotypes. It occurs at a high enough frequency, $\mathrm{f}(\mathrm{a} ;-)=0.119$, to be considered a "private polymorphism." Average per locus heterozygosity is estimated to be 0.053 . This value is not statistically different from levels observed on two modern urban populations. Thus, there is no evidence for a reduced level of genetic variation in these people, despite small parish sizes and a relatively unacculturated social structure.
\end{abstract}

The research presented here is an initial step toward relating the magnitude and patterning of heritable variation in two interbreeding human populations, the Gainj-and Kalam-speaking peoples of Papua New Guinea, to the juxtaposition of forces comprising their population breeding structure. Anthropological populations, like the Gainj and Kalam, are of evolutionary interest for two primary reasons. First, information regarding migration patterns, family relationships, mating preferences, and so forth, that would be impossible to obtain from natural populations of other organisms are more readily obtainable from human groups. As a result, the analysis of human population data allows us to test certain evolutionary hypotheses that might otherwise be untestable. Second, these groups are probably more reflective of certain conditions that shaped human evolution until quite recently, conditions that no longer exist within modern urban populations. Thus, it is helpful to study anthropological populations to understand the evolutionary meaning of contemporary human biological variation.

The Gainj and Kalam are recently contacted tribal swidden horticulturalists. They reside on the northern fringe of Papua New Guinea's central highlands and in adjacent portions of the Ramu River Valley. These two groups are linguistically distinct but otherwise very similar culturally. They inhabit a region that is ecologically diverse, rugged, and relatively inaccessible. Similar to other highland fringe populations (cf. Brown, 1978), they are among the most recent tribal people to have been contacted and studied.

\footnotetext{
Department of Biostatistics, Graduate School of Public Health, University of Pittsburgh, Pittsburgh, PA 15261.

Jammigumpula M. Naidu's present address is Department of Anthropology, Andra University, Waltair, India 53003

James W. Wood's present address is Population Studies Center, University of Michigan, Ann Arbor, MI 48109.

Received February 25, 1985; revision November 13, 1985.
} 
Both the Gainj and Kalam are subdivided into a series of local groups ranging in size from about 20 to almost 200 individuals. Each local group occupies a discrete territory, within which group members share access to garden land and forest resources. In keeping with long-standing usage among New Guinea social anthropologists (Hogbin and Wedgwood, 1952), these local groups are referred to as parishes. There are approximately 20 parishes in the Gainj population and an unascertained but larger number (perhaps $>100$ ) in the Kalam population. Both languages are spoken in a handful of admixed parishes. The Gainj are located in the Takwi River Valley and other nearby regions, while the Kalam are spread out over a considerably greater area, including the Asai, uper Simbai, and Kaironk Valleys (Majnep and Bulmer, 1977). Finally, a few Gainj and Kalam parishes are in the adjacent Ramu lowlands. The small black block in Figure 1 gives the location of the study area relative to the rest of Papua New Guinea.

It is difficult to determine when indirect contact between the Gainj and Kalam and the outside world began. A Catholic mission was established on the Ramu River, within 1 or 2 days' walk from the study area, during the $1930 \mathrm{~s}$. Direct and permanent contact was initiated in 1953 when an expedition into the area was launched from the newly established patrol post at Aiome. In 1959, the patrol post at Simbai was founded, and greatly increased rates of change followed.

By the early 1960s, population censuses were recorded, yaws had been eradicated, and the traditional pattern of intertribal warfare was ended. While mortality from warfare had been eliminated from the population, influenza was introduced and labor recruitment began. It is not known to what extent the change in disease pattern affected the demography of the population, but the effects of labor recruitment were quite severe.

Western contact within the study area has been enhanced by the establishment in 1969 of an Anglican mission at the northwest end of the Takwi Valley. An airstrip was constructed in 1970 and a school in 1974. In 1977, the Madang Province Department of Primary Industry introduced coffee as a cash crop (Wood, 1980). Before this time, the cash economy of the region depended solely on returning labor migrants. The mission, school, airstrip, and coffee gardening have resulted in a fair amount of acculturation.
Nevertheless, many aspects of life have retained their traditional orientation, and the settlement pattern and demographic profile appear quite stable (Wood, 1980; Wood and Smouse, 1982).

The population structure and dynamics of the Gainj and Kalam have been studied by our group since 1977. Our initial attraction to these populations grew from earlier anthropological investigations of Maring speakers in the nearby Simbai Valley (Rappaport, 1968; Buchbinder and Clark, 1971). Thus, the data reported here provide an additional link to a regional perspective of an. thropological populations in the western New Guinea highlands and highland fringe. The Gainj, Kalam, and neighboring groups are ideal for population genetic studies because the total number of individuals within defined geographical areas are small enough to permit nearly complete censuses and at the same time are large enough to allow meaningful statistical analyses.

Data have been collected on two field expeditions, the first in 1977-1978 and the second in 1982-1983. Cultural and biological information has now been obtained from a total of 28 parishes (Fig. 2). The 1977-1978 field expedition concentrated on the Takwi Valley region. In 1982-1983, the Takwi Val. ley parishes were revisited, and the study was extended into the Eastern Asai and Ramu Valleys.

A major focus of our research is on the relationship among Gainj and Kalam genetic structure and the cultural, demographic, and ecological factors that underlie it. The primary purpose of this article is to summarize and report the diverse data sets collected on the two field expeditions. Our specific objectives are 1) to describe the aspects of the demography and ecology that are the most relevant to population genetic analyses; 2 ) to outline our sampling framework, field meth. ods, and laboratory techniques; 3) to give an overview of the interparish dispersal pattern; 4) to present estimates of phenotype and allele frequencies for 600 individuals at 51 blood group, red cell enzyme, and serum protein loci; 5) to provide a genetic characterization of the population, including a compar. ison with other groups of New Guinea highlanders and initial descriptions of several new protein variants; and 6) to estimate the level of genetic variation in terms of the percentage of enzyme loci that are polymorphic and to estimate the average per locus heterozygosity. 


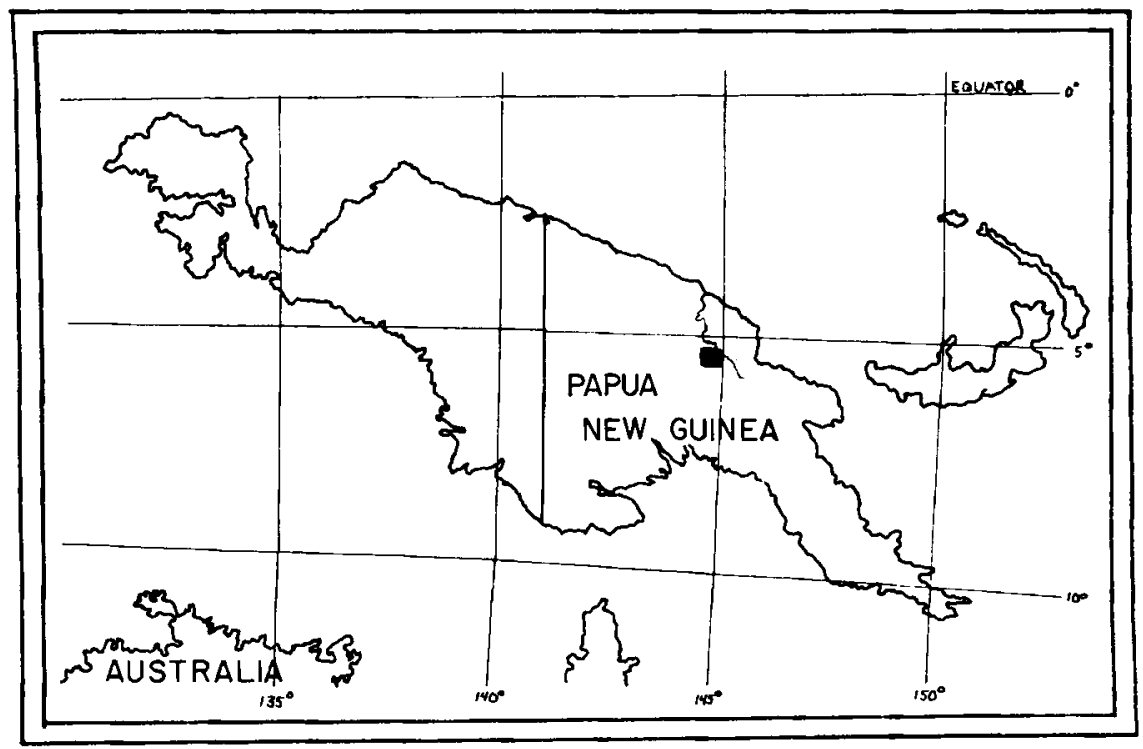

Fig. 1. The location of the study area (black box) relative to the rest of Papua New Guinea.

In subsequent articles we intend to establish levels of interparish genetic heterogeneity and to assess the relative roles of finite population size, migration, and the patterns of parish formation and extinction in the origin and maintenance of this heterogeneity. Our planned analyses include the use of new autocorrelation techniques developed by $R$. Sokal and his colleagues (Sokal and Oden, 1978a,b; Sokal and Friedlaender, 1983) and explicit comparison of observed genetic variation with predictions generated from new extensions of migration matrix theory (Bodmer and Cavalli-Sforza, 1968; Smith, 1969; Wood et al., 1985; Wood, in press).

\section{DEMOGRAPHY AND ECOLOGY}

Within the study area, changes in elevation are extreme. The Ramu lowlands lie at about $200 \mathrm{~m}$, while the rims of the Takwi and Asai Valleys rise to over $2,000 \mathrm{~m}$. The highland terrain is rugged, and the lowlands are characterized by low-lying relief and swamp. Neither the highland nor lowland portions of the study area are connected with other parts of Papua New Guinea by road, and a network of footpaths serves to interconnect the local parishes. Nonetheless, several small airstrips are maintained, and the area is serviced by light aircraft.

Rainfall in this region averages on the order of $500 \mathrm{~cm}$ a year. There is a wet season lasting from December until April and a nominally dry season lasting from June until September (Ford, 1974). The vegetation in the inhabited portions of the Asai and Takwi Valleys is lower montane rain forest, while the Ramu Valley is characterized by lowland hill forest and swamp (Paijmans, 1976). The people are primarily slash and burn horticulturalists, depending on gardens that are cleared and planted each year. Their diet is supplemented by hunting and gathering and by husbandry of pigs and chickens. The primary foods are sweet potato, taro, and yam. Western contact has introduced a few commercial foods; the most important are rice, tinned meat, and fish. Climatological and subsistence patterns of the Gainj and their Kalam neighbors are described in greater detail by Wood (1980).

The demography of the Takwi Valley portion of the study area has been described by Wood (1980) and Wood and Smouse (1982). In 1978 , the de facto population was 1,154 . Coupling this census figure with the estimated surface area $\left(44.8 \mathrm{~km}^{2}\right)$ leads to an estimated population density of 25.8 persons per kilometer. This is close to the figure $\left(24.4 / \mathrm{km}^{2}\right)$ given for the Simbai Valley Maring (Buchbinder, 1973), and it is probably typical of New Guinea highland fringe groups in general (Wood, 1980). The 1978 de jure population was 1,318 . The discrepancy between the 


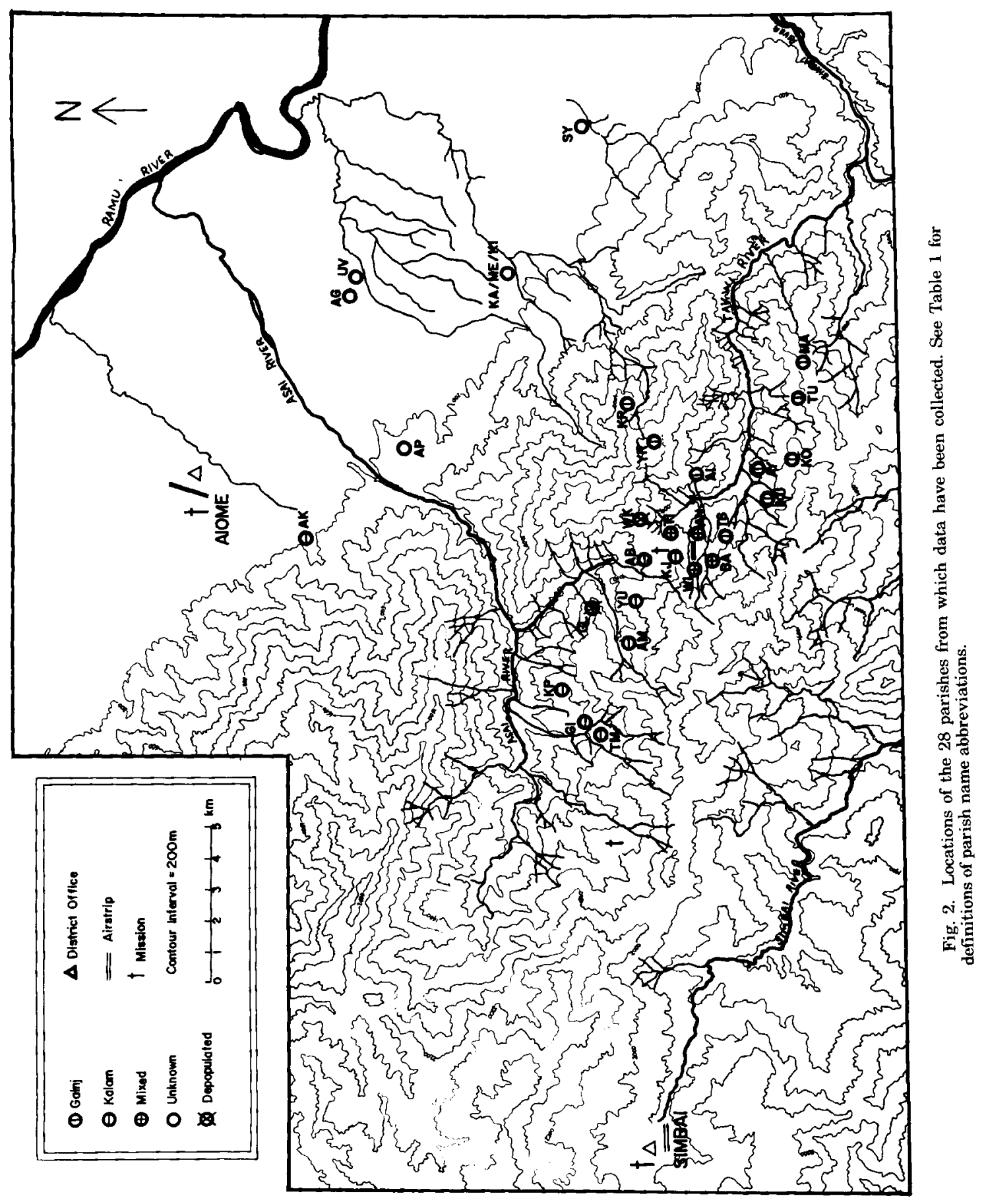


de facto and de jure figures is almost totally due to male absenteeism associated with plantation work. The labor migrants are gone for periods ranging from 2 to 10 years, but they usually do not permanently emigrate. The population size has been judged to be density regulated (via mortality) and near its carrying capacity (Wood and Smouse, 1982). We do not know as much about the demography of the ecologically similar Asai Valley population; however, it does not seem to differ with respect to general factors such as population density or absenteeism.

By contrast, the Ramu Valley region occupied by the Kalam and Gainj has a strikingly lower population density. This is readily apparent when comparing the census figure in Table 1 with the geographic layout in Figure 2 . The difference is interesting because much of the Ramu Valley is suitable for gardening, the sago palm is an abundant food source, and the lowland rivers, unlike the higher portions of the Takwi and Asai Rivers, have sizable fish populations. Additionally, there appear to be more abundant game resources in the lowlands. Nevertheless, malaria and filariasis are endemic diseases in the Ramu Valley, and this may limit population density. Malarial infections occurring in the highland people are often attributed to trips to the Ramu Valley, and both highland and lowland people agree that "sickness" is more of a problem in the lowlands.

Settlement within a parish is widely dispersed rather than aggregated. The larger parishes we have sampled are actually collections of small hamlets. These small hamlets tend to align and realign with different parishes somewhat frequently. This dispersed settlement pattern is typical of much of the New Guinea highlands and the highland fringe (Gajdusek and Alpers, 1972; Brown, 1978). Nevertheless, bachelor houses and ritual dance structures serve as foci of social and political activity. Thus, the parish is provided with social integrity beyond shared access to resources.

In the establishment of marriages, people attempt to ensure that each person will have affinal ties with as many parishes as possible (Johnson, 1982). Among other things, this system results in an avoidance of marriage to close relatives. About 19\% of married men are polygynous, usually having two wives. A small percentage of men have three wives, and one man is known to have had four wives simultaneously. There are prevailing rules of parish exogamy and patrilocal postmarital residence (Johnson, 1982), but these ideals are flexible. About $11 \%$ of marriages are endogamous, and the patrilocal rule is sometimes violated. Some of this flexibility may be due to the fact that each individual has access to garden land in the natal parishes of all four of his or her grandparents.

There is variation among parishes in both population size and territory controlled. Additionally, it is apparent from comparisons of 1978 and 1983 census information that shortterm variation in both these features may also occur within a single parish. Some of this variation is due to shifting alliances of the smaller hamlets. Finally, several events of parish formation and extinction are known to have occurred over the past few decades, and it is unlikely that the half-life of a parish is much more than two generations. An interesting feature of parish dynamics is that the number of parish formations has been more or less balanced by the number of parish extinctions (Wood, 1980). It thus seems that both the number of parishes and the number of individuals are maintained near equilibrium.

\section{MATERIALS AND METHODS Data collection}

Several kinds of cultural, demographic, and biological information have been collected on the study population. These include census counts, blood samples, and anthropometric measurements. The 1977-1978 expedition concentrated on 12 parishes in the Takwi Valley. In 1982-1983, these parishes were revisited and recensused. Blood samples and anthropometrics were requested from individuals who had not participated in the earlier study. The study area was then extended to include one new parish in the Takwi Valley and several new parishes in the Eastern Asai and the Ramu Valleys. Each parish visited, the year(s) it was visited, population size, and types of information collected are listed in Table 1. All aspects of the demographic and genetic data collected in the 1977-1978 field season have been previously reported (Wood, 1980; Johnson, 1981, 1982; Wood et al., 1982). This article will concentrate on the 1982-1983 field results and on how these can be unified with the 1977-1978 results into a single data set.

\section{Demographic data}

Takwi Valley parishes were surveyed between September and December of 1982. The Ramu and Asai Valley parishes were visited 


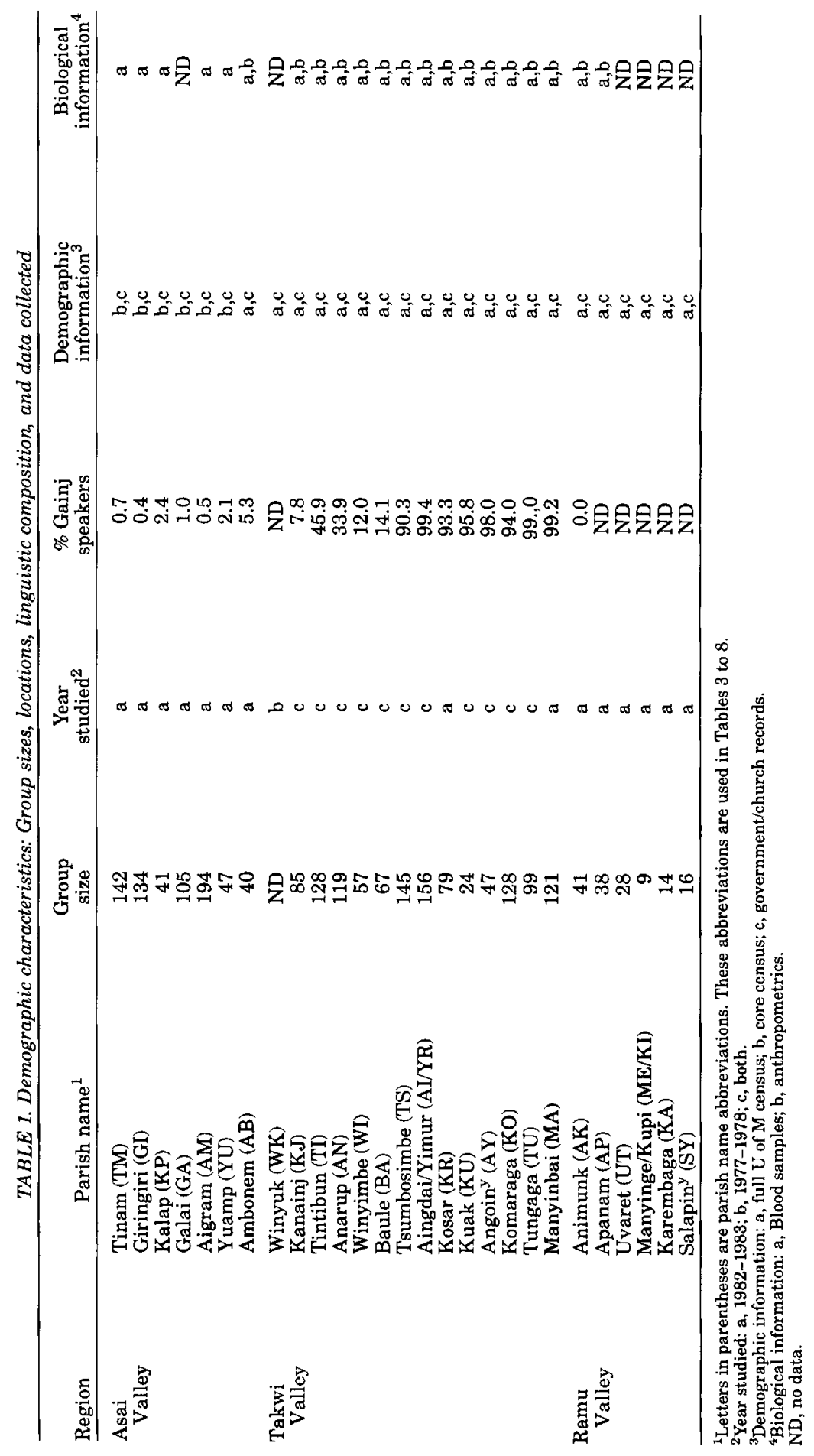


between January and May of 1983. The strategy of our investigation was to visit each parish and to obtain a basic core of information, including 1) as complete an enumeration of members as possible, 2) household membership of each person, 3) sex of each person, 4) place of birth, and 5) an individual's mother's and father's places of birth. Individuals from the Asai and Takwi Valley parishes were polled as to their primary linguistic affiliation (Kalam or Gainj). The linguistic composition of each parish is also given in Table 1. In a selected group of parishes (primarily in the Takwi and Ramu Valleys), this core of information was augmented by additional information on the age and reproductive history of each individual, as well as other types of demographic characteristics. The methods of ascertainment for this information are described by Wood (1980).

Our last sources of demographic information are government and church records. Censuses have been conducted sporadically by the district officers at Simbai and at Aiome since the early $1960 \mathrm{~s}$, and some baptismal records are kept at the Kanainj Anglican Mission. We have copied these documents, and they serve as a convenient reference base.

\section{Biological data}

Blood samples and anthropometric data were collected on visits to each parish subsequent to the census. The people were requested to participate by allowing us to take a blood sample and eight anthropometric measurements (weight, height, head circumference, chest circumference, mid-upper arm circumference, and triceps and subscapular skinfolds). (The anthropometric measurements were taken from individuals of all ages, and a complete report is in preparation. Meanwhile, these data are available on request to qualified investigators.) Blood samples were taken only from healthy individuals judged to be between 10 and 60 years old. Eruption of the first maxillary premolar was taken as evidence that a person was at least 10 years of age (Malcolm, 1970). Our assessment of the 60-year upper age boundary was more subjective and probably associated with considerable error. Blood samples were also collected from children over 10 years who were attending government schools located at local missions. Only those students who resided in villages within our previously defined study area were requested to participate. A total of 281 blood samples were collected.
Two 15-ml samples of venous blood were drawn from each individual into vacutainer tubes without anticoagulant. All specimens were kept as cool as possible in polystyrene boxes with ice for periods up to 48 hours while waiting to be centrifuged by hand in the field. Following centrifugation, plasma, red cell, and buffy coat portions were placed in 2-ml cryovials and stored in liquid nitrogen. A portion of the red blood cells was frozen in a glycerol-sorbitol solution to facilitate blood group typing (Weiner and Lourie, 1981). Finally, the blood samples were shipped to Ann Arbor either in liquid nitrogen or on dry ice. The shipping method did not affect blood protein typings. However, red cell antigen typings were impossible for some samples shipped on dry ice despite the fact that thawing had not occurred. After arrival, the samples were stored at $-72^{\circ} \mathrm{C}$ or less until the laboratory determinations were performed.

\section{Blood groups}

Single typings were performed on red cells that had been preserved in glycerol-sorbitol freezing solution in liquid nitrogen. The following systems were investigated: $\mathrm{ABO}, \mathrm{Rh}$, MNSs, Kell (K), Duffy (Fy), Kidd (Jk), Diego (Di), and Lewis (Le). The procedures used have been described previously (Gershowitz et al., 1972).

\section{Plasma proteins}

Albumin (ALB), transferrin (Tf), haptoglobin (Hp), and ceruloplasmin (CRPL) typings were done by polyacrylamide gel electrophoresis following the technique of Maurer and Allen (1972). Staining procedures were as described by Tanis et al. (1973). The $\mathrm{Gm}$ and $\mathrm{Km}$ system typings followed the procedures of Gershowitz and Neel (1978). Group Specific Component $(\mathrm{Gc})$ was typed as described by Greenbaum et al. (1977).

\section{Erythrocyte proteins}

The following 27 erythrocyte proteins were examined for variants by either starch gel or polyacrylamide gel electrophoresis: hemoglobin A-1 (HbA-1), hemoglobin A-2 (Hb A-2), acid phosphatase-1 (ACP1), adenosine deaminase (ADA), adenylate kinase-1 (AK1), carbonic anhydrases 1 and 2 (CA1, CA 2), esterases A, B, and D (ESA, ESB, ESD), galactose-1-phosphate uridyl transferase (GALT), glucose-6-phosphate dehydrogenase (G6PD), glutamate oxaloacetate transaminase-s (GOTS), hexokinases I and II ( $\mathrm{Hk}, \mathrm{I}, \mathrm{Hk} \mathrm{I})$, isocitrate dehydrogenase (ICD), lactate de- 
hydrogenase (LDH A, LDH B), malic dehydrogenase (MDH), nucleoside phosphorylase (NP), peptidases A, B, C, and D (PEPA, PEPB, PEPC, PEPD), 6-phosphogluconate dehydrogenase (6PGD), phosphoglucomutase I and II (PGM1, PGM2), phosphoglucoisomerase (GPI), phosphoglycerate kinase (PGK), and triosephosphate isomerase (TPI). The methods have been previously described by Neel et al. $(1977,1980)$ and by Barrantes et al. (1982). Glyoxalase (GLO) was typed from the esterase buffer system. Glutamic-pyruvate transaminase (GPT) and fumarase (FUM) were typed from a horizontal acrylamide system, using a histidine-citrate $(0.005$ M, pH 7.4) gel buffer and a Tris-maleic acid (0.1 M, pH 7.5) electrophoresis buffer. Superoxide dismutase (SOD) was typed as described by Brewer (1967).

\section{RESULTS \\ Complete data set}

In addition to the 281 blood samples collected in 1982-1983, 319 blood samples were collected on the first field expedition. Typings were performed on the samples from the first collection for the following systems: $\mathrm{ABO}, \mathrm{Rh}, \mathrm{MN}, \mathrm{P}$, Gerbich (Ge), hemoglobin $\mathrm{A}(\mathrm{Hb} \mathrm{A})$, lactate dehydrogenases $\mathrm{A}$ and $\mathrm{B}$ (LDH A, LDH B), superoxide dimutase (SOD), phosphoglucomutase I and II (PGM 1 and 2), 6-phosphogluconate dehydrogenase (6GPD), glutamic pyruvic transaminase (GPT), esterase $\mathrm{D}$ (ESD), adenosine deaminase (ADA), acid phosphatase-1 (ACP), phosphoglycerate kinase (PGK), malate dehydrogenase (MDH), albumin (Alb), haptoglobin (Hp), and transferrin (Tf). These typings were done in the laboratories of R.L. Kirk in Canberra, Australia and K. McLoughlin in Christchurch, New Zealand. The collection and typing procedures for the 1977-1978 samples were described by Wood et al. (1982).

\section{Demographic results}

The demographic data collected during the 1983 field season have allowed us to examine the pattern of dispersal between parishes within the study population (Wood et al., 1985). We have structured our analyses in terms of the joint distribution of birth places of parents and their offspring. The pattern can be characterized as follows. Some $83.7 \%$ of all individuals sampled were born in the father's natal parish, while only $33.2 \%$ were born in the natal parish of their mother. These figures reflect both the prevailing patrilocal rule of postmarital residence and the fact that some marriages are endogamous. The mean distance between the birthplaces of fathers and their offspring is only $1.3 \pm$ $0.1 \mathrm{~km}$ compared to $4.2 \pm 0.2 \mathrm{~km}$ for mothers and their offspring. Despite the geographic restriction on the parent/offspring distribution of birthplaces, all of the parishes exchange mates with other nearby Kalam and Gainj parishes that we have not yet studied. Thus, while our study population is affected to a remarkable degree by isolation by distance (cf. Wright, 1943; Morton, 1969), it is not a geographic isolate in the strict sense of the word.

We have found that the dispersal of both males and females is negatively density dependent. By this we mean that there is a tendency for individuals born in parishes with high population density to reproduce in parishes with lower density. This may have the effect of smoothing out minor demographic disturbances that typically occur in small subdivided populations. Finally, we note that the linguistic composition of the parishes is an important determinant of pairwise migration rates. Sex-specific migration matrices and a complete analysis of the dispersal pattern are presented elsewhere (Wood et al., 1985).

\section{Genetic results}

Combining the two sets of genetic data, 600 individuals have been sampled and 51 genetic systems have been tested on varying portions of the total sample. Twenty-five of the loci were found to be invariant. These are listed in Table 2, along with the number of individuals tested and the designation of the fixed allele. In Tables 3-5, phenotype counts are given for each parish. To combine the two data sets, it was necessary to reconcile the

TABLE 2. Fixed loci

\begin{tabular}{|c|c|c|c|c|c|}
\hline Locus & $\mathrm{N}$ & $\begin{array}{l}\text { Fixed } \\
\text { allele }\end{array}$ & Locus & $\mathbf{N}$ & $\begin{array}{l}\text { Fixed } \\
\text { allele }\end{array}$ \\
\hline Kell & 86 & $\mathrm{~K}$ & $\mathrm{ICD}^{1}$ & 277 & Normal \\
\hline Diego & 54 & $D i^{b}$ & $\mathrm{AK}^{1}$ & 277 & 1 \\
\hline CRPL $^{1}$ & 281 & $\mathrm{~B}$ & $\mathrm{G} \mathrm{PD}^{1}$ & 278 & $\mathbf{B}$ \\
\hline Alb $^{1}$ & 594 & Normal & $\mathrm{Hb}-\alpha^{1}$ & 588 & Normal \\
\hline $\mathrm{CA}{ }^{1}$ & 274 & Normal & $\mathrm{Hb}-\beta^{1}$ & 588 & Normal \\
\hline $\mathrm{CA} 2^{1}$ & 277 & Normal & $H b-\delta^{1}$ & 277 & Normal \\
\hline $\mathrm{ESA}^{1}$ & 275 & Normal & GALT $^{1}$ & 276 & Normal \\
\hline $\mathrm{ESB}^{1}$ & 273 & Normal & GLO & 275 & 2 \\
\hline LDH $\mathbf{A}^{1}$ & 589 & Normal & GOTS $^{1}$ & 277 & $\mathbf{1}$ \\
\hline $\mathrm{LDH} \mathrm{B}^{1}$ & 589 & Normal & SOD $^{1}$ & 588 & 1 \\
\hline PEP B $^{1}$ & 275 & Normal & $\mathrm{TPI}^{1}$ & 277 & 1 \\
\hline PEP C $^{1}$ & 271 & Normal & $\mathrm{Hk}^{\mathbf{1}}$ & 274 & 1 \\
\hline $\mathrm{PEP} \mathrm{D}^{1}$ & 281 & Normal & $\mathrm{Hk} \mathrm{II}^{1}$ & 273 & 1 \\
\hline
\end{tabular}

${ }^{1}$ Locus has been used to calculate average heterozygosity. See text for details. 
1977-1978 sample with the demographic changes that occurred between the time of its collection and the most recent census in May 1983. The following changes occurred during this time interval. Eight of the 319 people sampled for blood genetic markers died, and three married outside of the study area and hence emigrated. Since these individuals can no longer be considered part of the potential breeding population, they have been excluded from the counts in Tables 2-5. Three members are currently attending national high schools outside the study area and 22 are working on plantations. These people are treated as temporary emigrees and are included as part of the genetic sample from their 1977-1978 parish of residence. Finally, twenty-five members of the group switched from their 1977-1978 parish of residence to another parish within the study area. These persons are included in their 1982-1983 parish of residence.

Allele and haplotype frequencies obtained from the combined phenotype counts in Tables 3-5 are given for the individual parishes and the total population in Tables $6-8$. The total population frequencies are averages weighted by the sample size within each parish. All allele and haplotype frequencies are estimated obtained by the method of maximum likelihood (cf. Li, 1976). For codominant systems such as the red cell enzymes and serum proteins (excluding $\mathrm{Gm}$ ), gene counting yields the maximum likelihood estimates. The blood groups $\mathrm{P}, \mathrm{Le}$, and Ge are two allele systems with dominance. For these loci, the maximum likelihood estimates of allele frequencies are obtained by the square root method. The Fy and $J k$ blood groups were tested only with anti-Fy ${ }^{a}$ and anti-Jk ${ }^{a}$ for the 1978 collection but with both antisera, anti-Fy ${ }^{a}, F^{b}{ }^{b}$ and anti-Jk ${ }^{a}, J k^{b}$, for the 1983 collections. To combine the two data sets, it is necessary to discard the anti-Fyb and anti-Jk ${ }^{\mathrm{b}}$ information and to estimate allele frequencies using the square root method. The MN system has been typed uniformly with anti-M,N,S,s for the 1983 sample, but anti-S,s typings are missing for some of the 1978 material. Consequently, only the $\mathrm{M}$ and $\mathrm{N}$ allele frequencies are reported. These are obtained by gene counting as described above. ABO, Rh, and Gm allele and haplotype frequencies are obtained via iterative maximum likelihood methods.

\section{POPULATION CHARACTERIZATION}

The 1983 blood collection data corroborate the view of Wood et al. (1982) that the popu- lation as a whole displays genetic characteristics typical of "non-Austronesian" populations of the interior highlands of New Guinea. These characteristics can be summarized as follows: $\left.\mathrm{f}\left(\mathrm{A}^{1}\right)>\mathrm{f}(\mathrm{B})>0.10 ; \mathrm{f}^{1} \mathrm{R}^{1}\right)$ $>0.85$; $\mathrm{f}(\mathrm{M})<0.05$; $\mathrm{f}(\mathrm{MS})$ negligible or absent; $\left.\mathrm{f} \mathrm{Hp}^{1}\right)>0.60 ; \mathrm{f}\left(\mathrm{PGM}_{1}^{1}\right)>0.90 ; \mathrm{MDH}^{3}$ and $\mathrm{PGK}^{4}$ present at low frequency; and $\mathrm{PGM}_{2}^{9}$ and $\mathrm{ESD}^{2}$ variants both present at polymorphic frequencies (Buchbinder and Clark, 1971; Simmons and Booth, 1971; Omoto and Blake, 1972; Howells, 1973; Kirk et al., 1973; Woodfield et al., 1974; Blake and Omoto, 1975; Blake, 1976, 1978; Curtain, 1974). The genetic characterization of the population can be extended by considering the 33 loci, reported here for the first time.

\section{Blood group loci}

The new blood groups are P, Kell, Ge, Kidd, Fy, and Di. Eighty-six samples were tested with anti-K and 54 with both anti-Di ${ }^{\mathrm{a}},-\mathrm{Di}^{\mathrm{b}}$. All samples were Kell negative and $\mathrm{Di}^{\mathrm{a}}$ positive- $\mathrm{Di}^{\mathrm{b}}$ negative. These results are in accordance with data from investigations in both the Eastern and Western Highlands (Simmons et al., 1972; Sinnett et al., 1970). The $P^{1}$ allele frequency, $f\left(P^{1}\right)=0.0461$, is low relative to the frequency observed at Bundi, $f\left(P^{1}\right)=0.1034$ (Malcolm et al., 1971), and the Eastern Highlands, $f\left(\mathbf{P}^{1}\right)=0.2000$ (Simmons et al., 1972). Our observations for Le, based solely on 53 individuals sampled in the Ramu Valley, yield 0.1325 as an estimate of the Le allele frequency. This figure differs markedly from the $f(L e)=0.5331$ estimate in the Eastern Highlands (Simmons et al., 1972). The significance of this divergence is obscure, given the absence of other comparative data. The Gerbich blood group is a strong polymorphism in this population. The Gainj and Kalam are enigmatic with respect to this because $\mathrm{Ge}(\mathrm{a}-)$ is usually absent among highlanders while common among people in Morobe, the Sepik, and the Madang coast (Booth et al., 1971a-c). The most surprising finding is that of a single $\mathrm{Fy}^{\mathrm{b}}$-positive individual. This phenotype has been found in neither the Eastern nor Western Highlands (Sinnett et al., 1970; Simmons et al., 1972), but low levels of $\mathrm{Fy}^{\mathrm{b}}$ in the South Pacific are not unprecedented. Simmons et al. (1972) have observed it infrequently in New Britian, the Solomon Islands, and Australia, and it has been reported to have a frequency of $f\left(F^{b}\right)=0.3000$ in the Wissel Lake area of West Irian (Howells, 1973).

\section{Serum proteins}

In addition to $\mathrm{Hp}, \mathrm{Tf}$, and $\mathrm{Alb}$, four new 


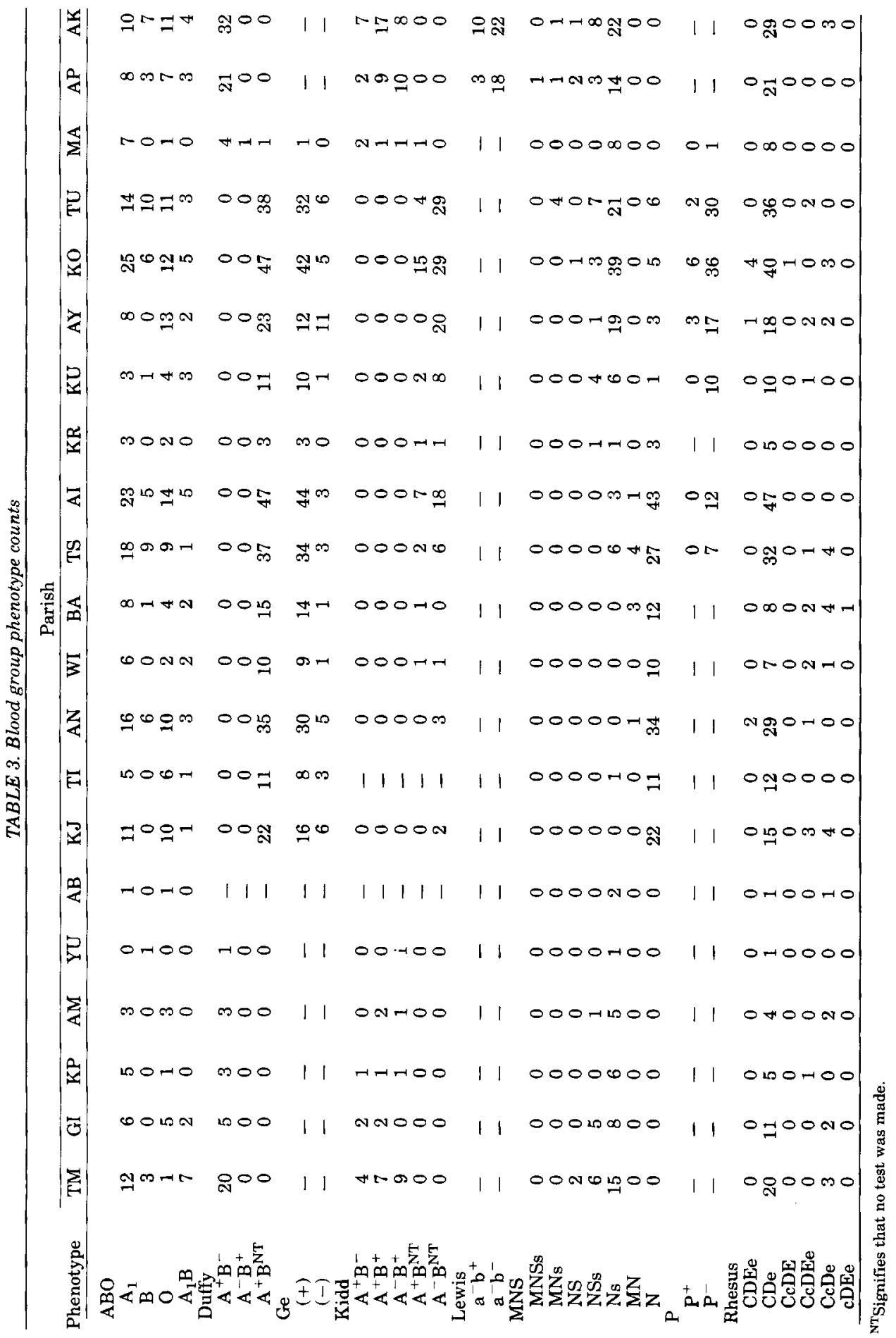




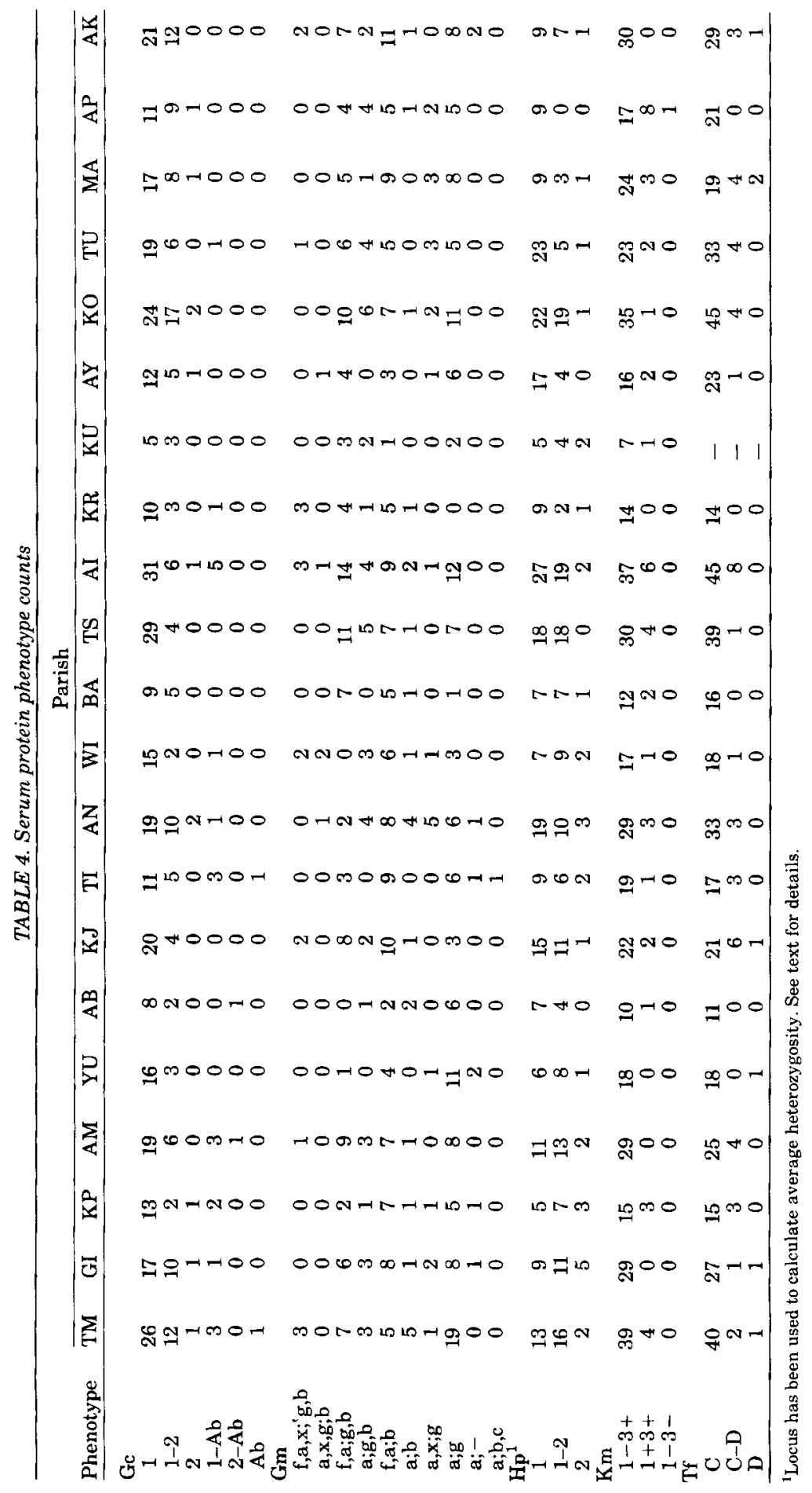




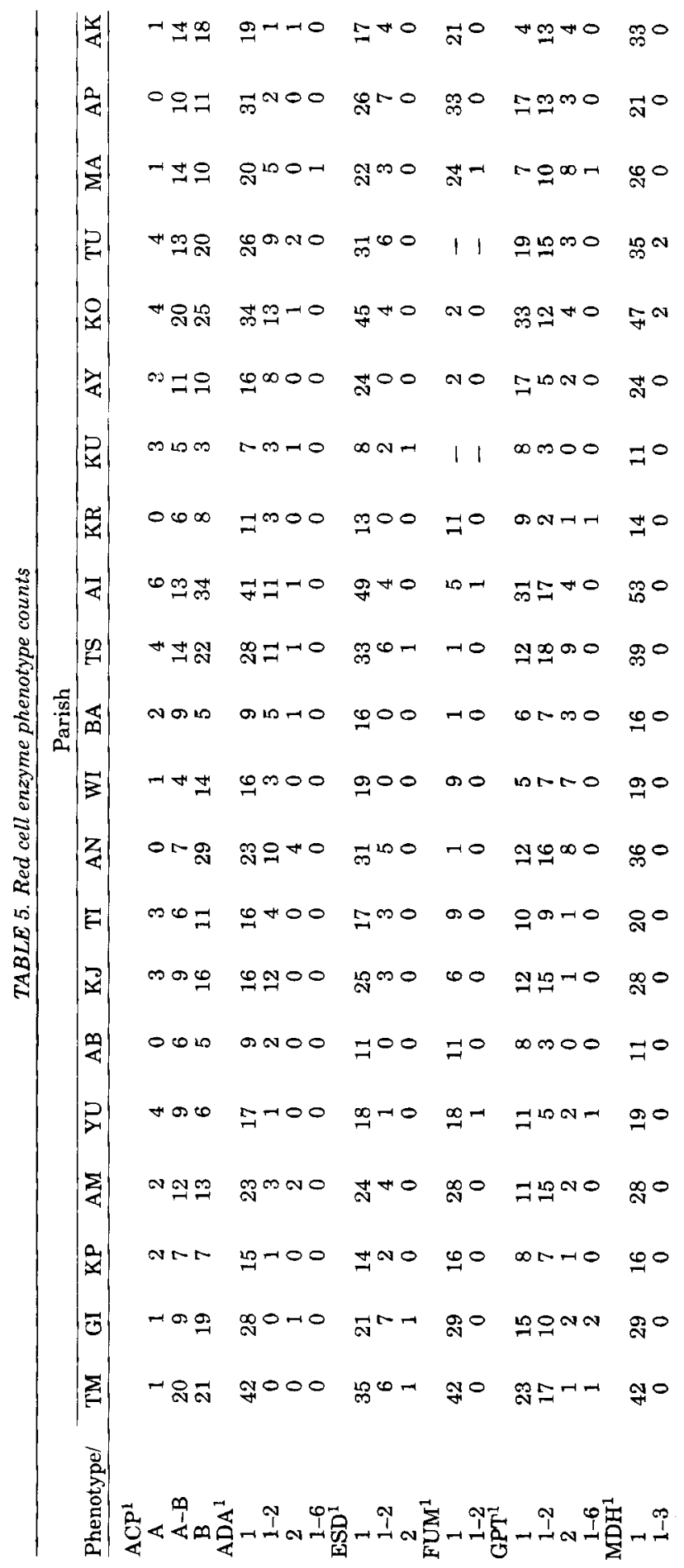




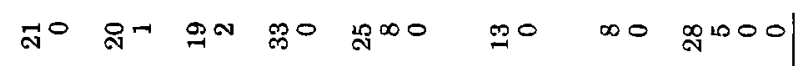

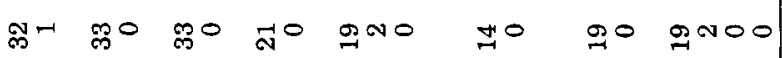

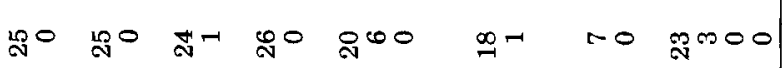

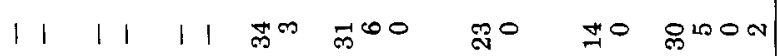

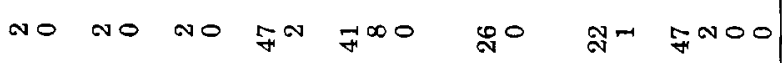

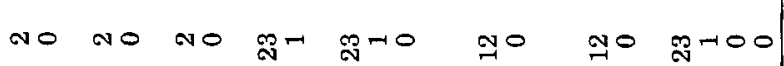

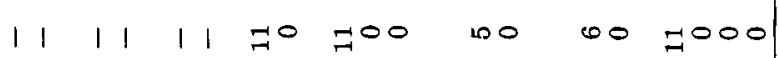

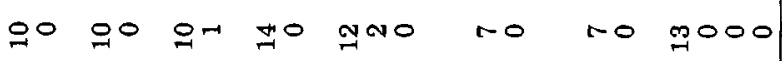
DO 10 lo 年 TO to to gr to to to

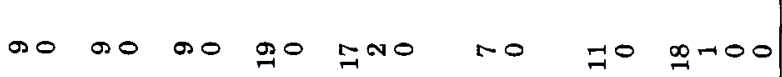

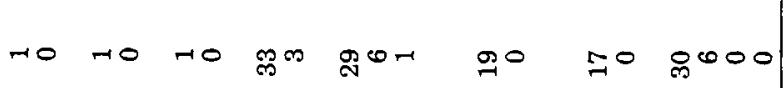

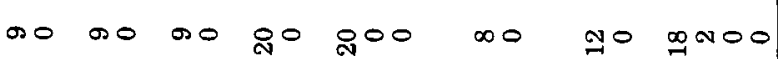

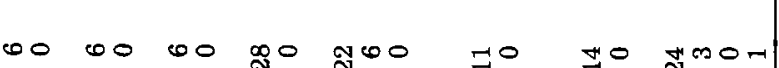

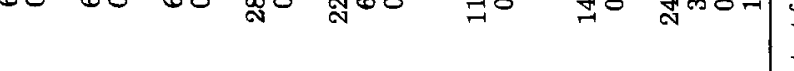

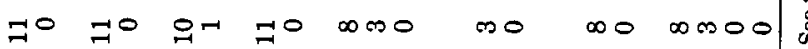

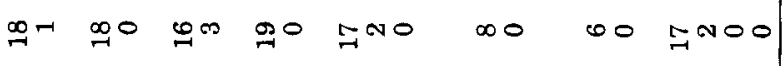

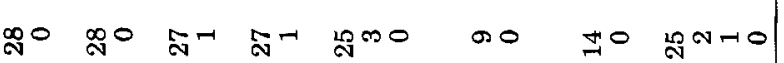
mo

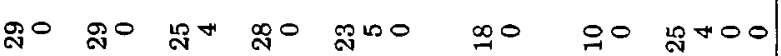

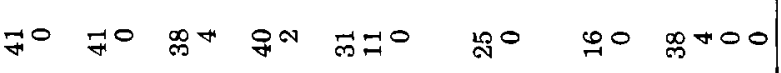

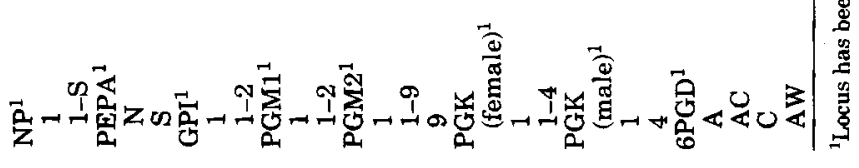




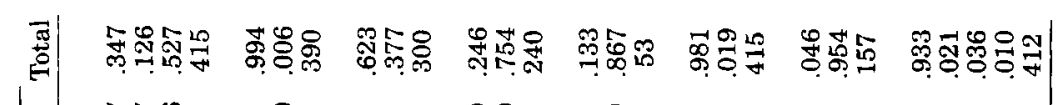

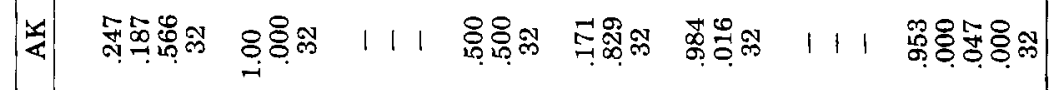

₹

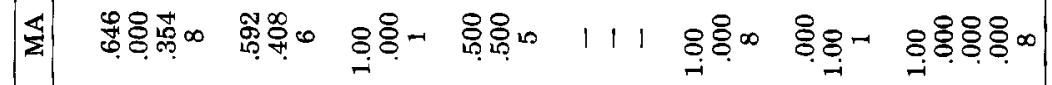

란

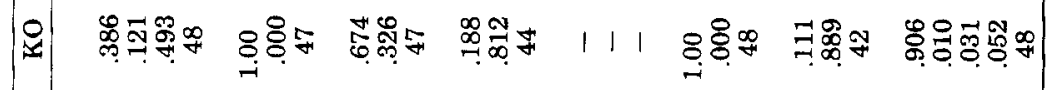

₹ ₹

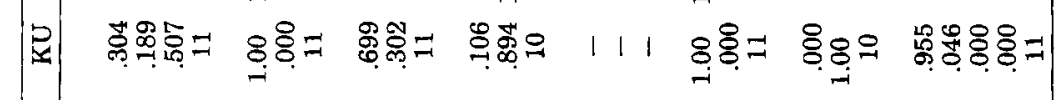

\%

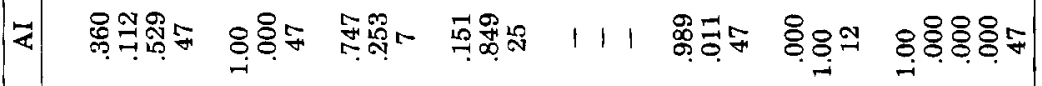

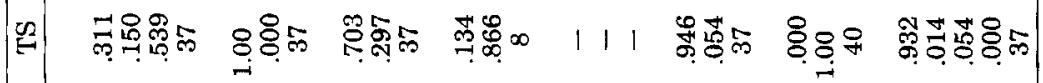

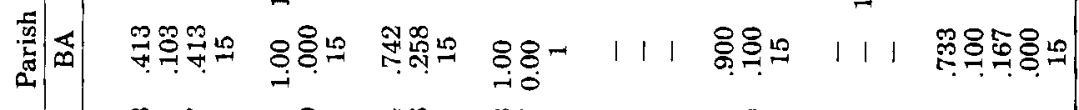

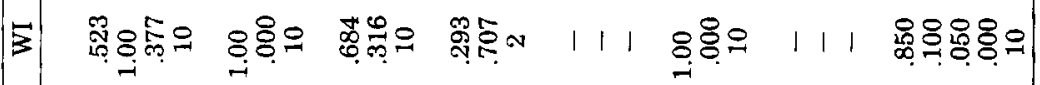

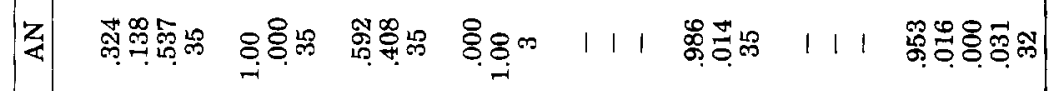

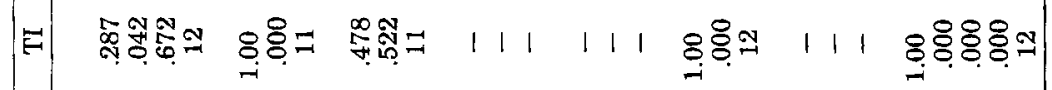

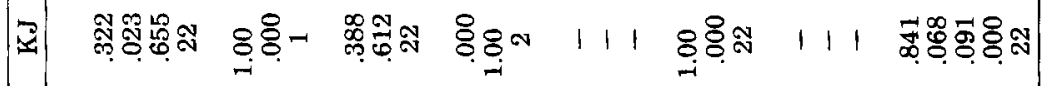

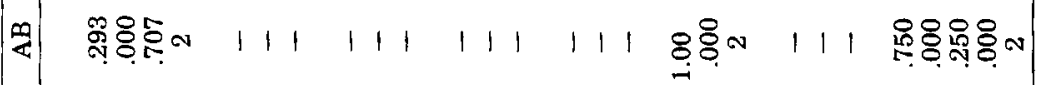

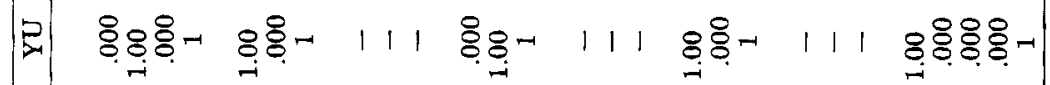

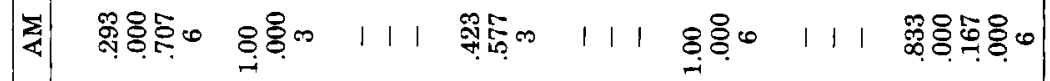

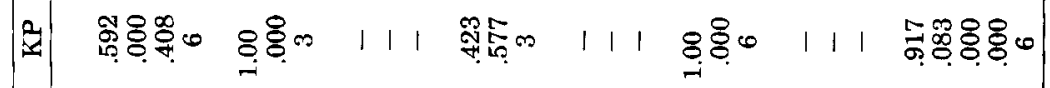

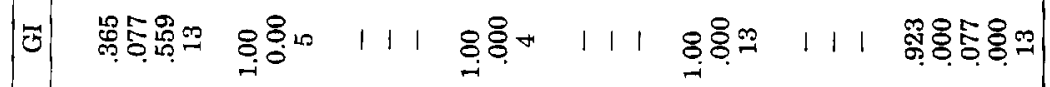

క.

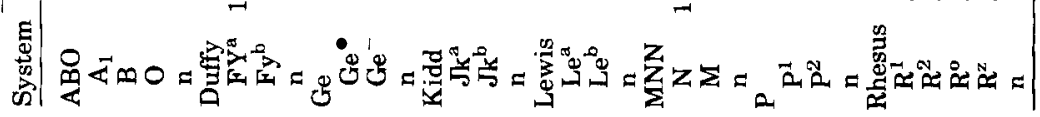




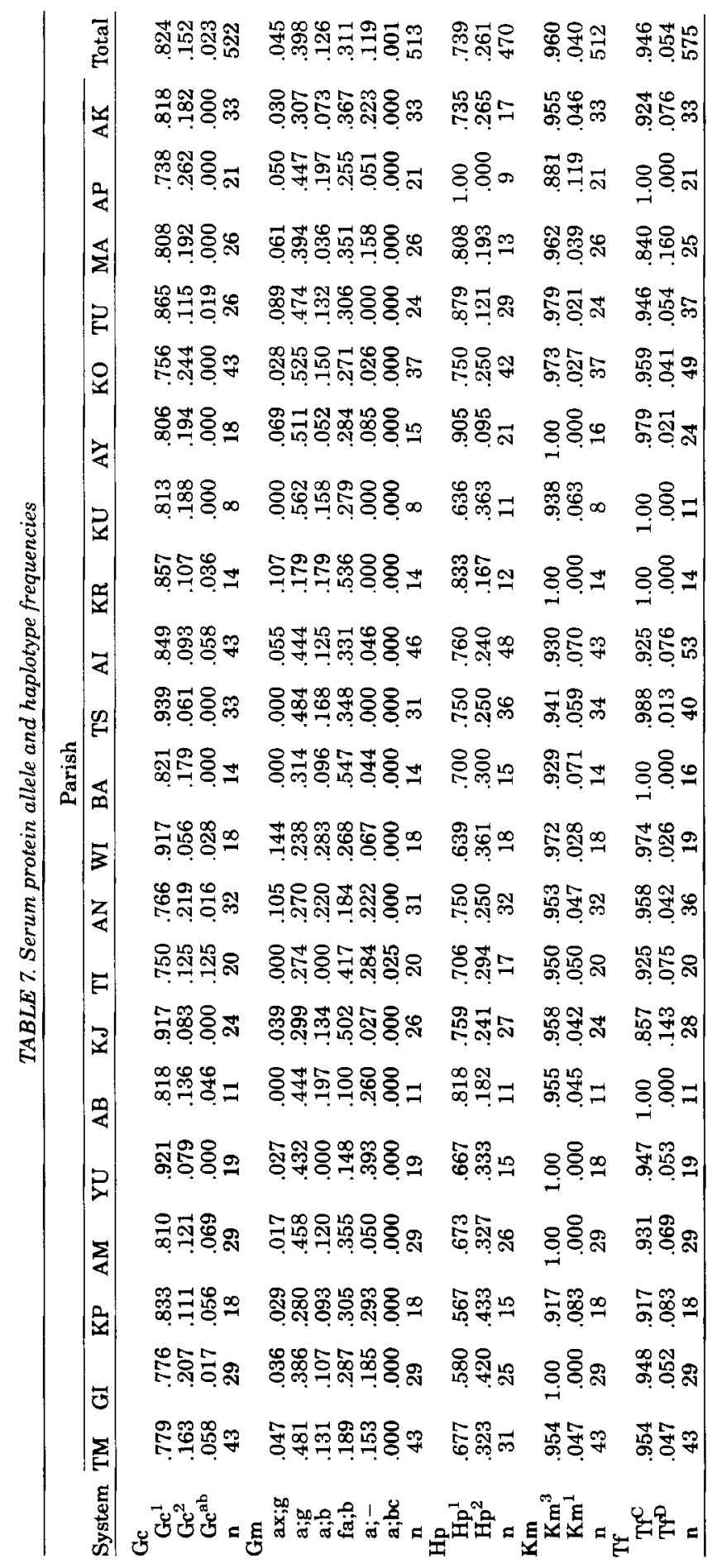




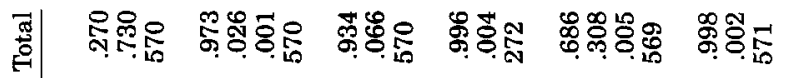

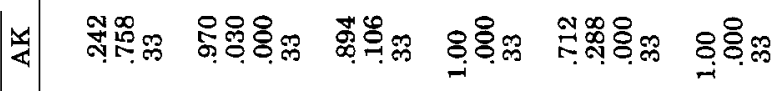

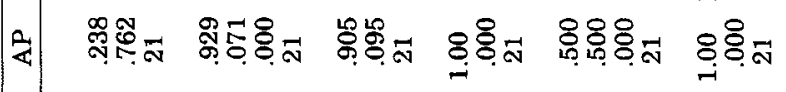

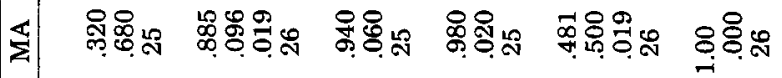

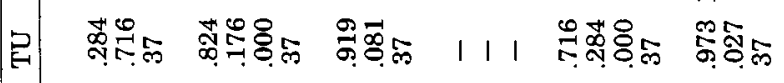

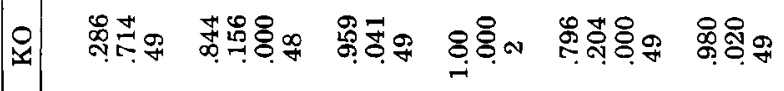

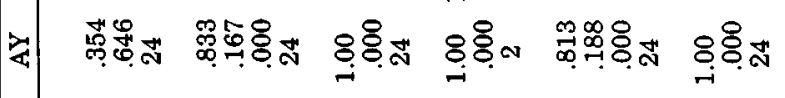

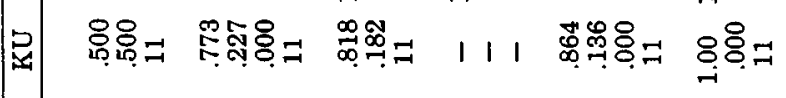

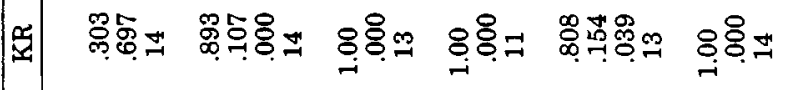

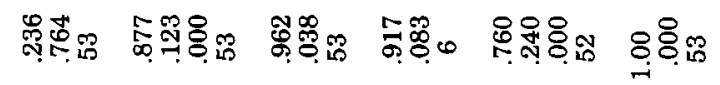
눈워

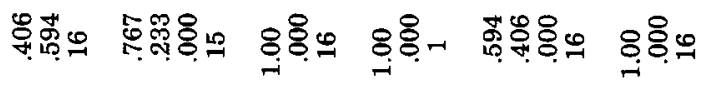

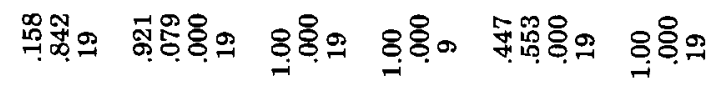

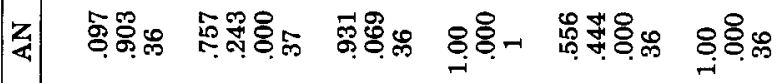

|

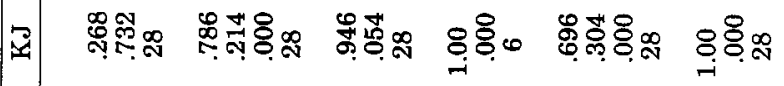

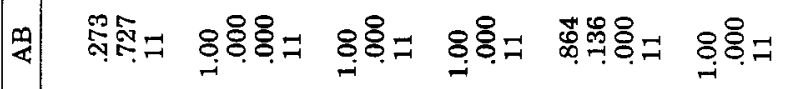

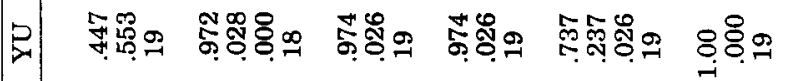

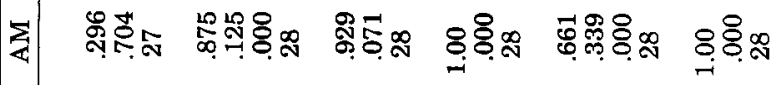

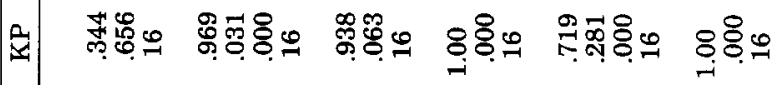

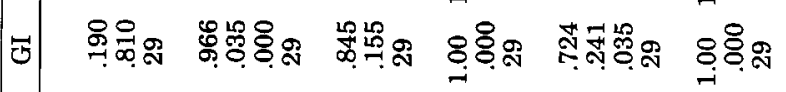

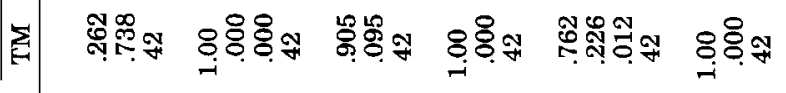

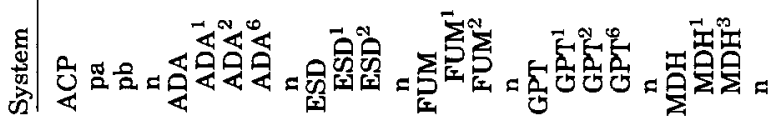




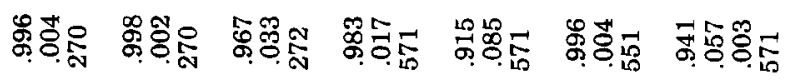

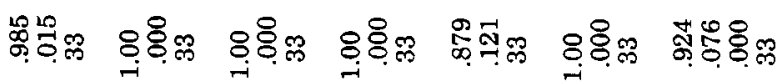

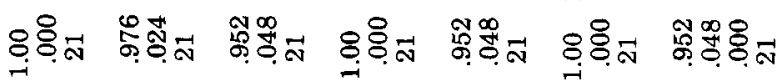

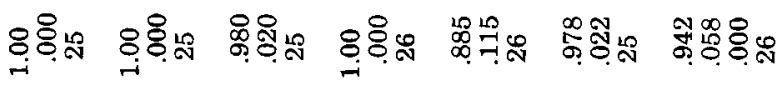

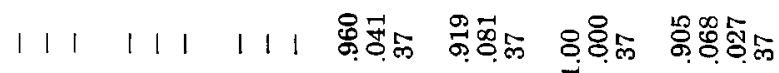

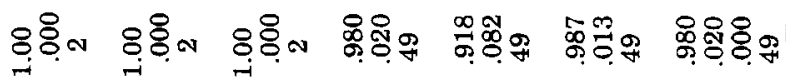

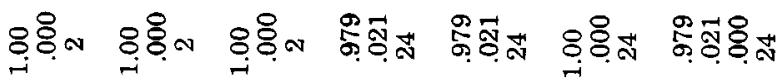
111111111 8\%

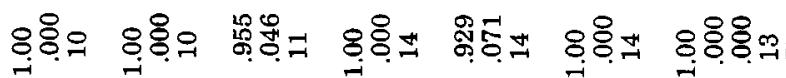

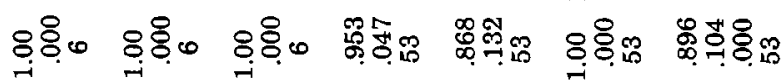
\%

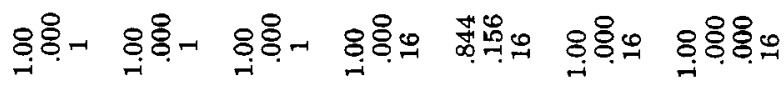

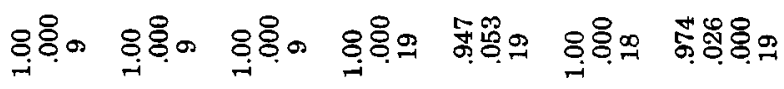

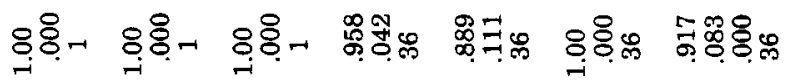

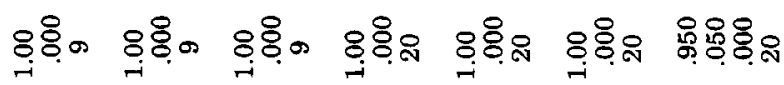
๑

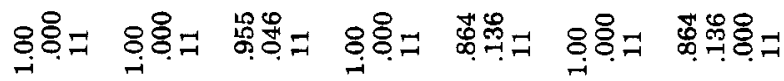

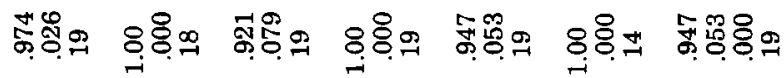

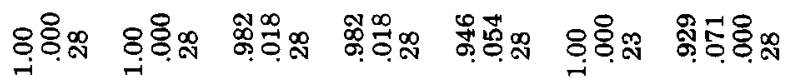

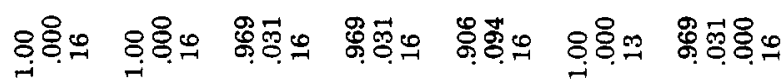

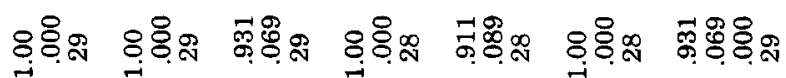

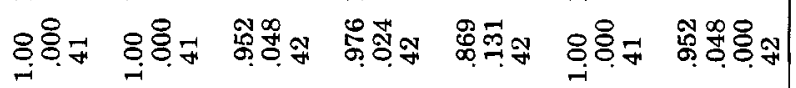

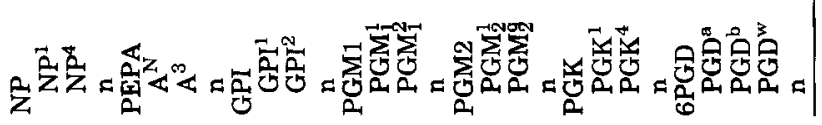


serum proteins, CRPL, Gc, Gm, and $\mathrm{Km}$, have been typed for the 1983 collection. No ceruloplasmin variants $(\mathrm{N}=281)$ were identified. The world-wide variants of the Gc systems, $\mathrm{Gc}^{1}$ and $\mathrm{Gc}^{2}$, are usually accompanied by a third allele, $\mathrm{Gc}^{\mathrm{Ab}}$ (Aborigine), in Australia and Papua New Guinea. All three alleles reach polymorphic frequencies among the Gainj and Kalam. The frequency of $\mathrm{Gc}^{\mathrm{A}}$, $\mathrm{f}(\mathrm{Ab})=0.0290$, is low relative to the island of New Guinea as a whole and other highland populations, which have average frequencies in the neighborhood of $f(A b)=$ 0.0700 (Kitchin et al., 1972). The common alleles, $\mathrm{Gc}^{1}$ and $\mathrm{Gc}^{2}$, vary in frequency widely over New Guinea, but a discernible ecological or regional pattern has not been identified (Curtain, 1974).

In terms of immunoglobulin light-chain variants, $\mathrm{Km}$ (Inv), the Gainj and Kalam fit comfortably among other highland groups, with $\mathrm{f}\left(\mathrm{Km}^{1}\right)<0.05$. The frequency of $\mathrm{Km}^{1}$ rises in regions to both the east and west of the central highlands (Schanfield, 1971) and becomes quite high in New Britian and the Solomons (Friedlaender and Steinberg, 1970). The immunoglobulin heavy-chain variants, $\mathrm{Gm}$, present a complex picture. The specificities for $\operatorname{Gm}(\mathrm{a}),(\mathrm{x}),(\mathrm{f}),\left(\mathrm{b}^{1}\right),\left(\mathrm{b}^{0}\right),\left(\mathrm{b}^{3}\right),(\mathrm{t}),(\mathrm{g})$, $\left(c^{3}\right)$, and $\left(c^{5}\right)$ were tested according to the methods used by Gershowitz and Neel (1978). The notation of phenotypes and haplotypes conforms to the recommendations made by the W.H.O. Committee on Human Immunoglobulin Allotype Markers (1976). A total of ten phenotypes were observed (Table 3). In accord with other studies, Gm(t) was always absent and $\operatorname{Gm}\left(b^{0}\right),\left(b^{1}\right)$, and $\left(b^{3}\right)$ were either simultaneously present or absent. We have collapsed these specificities into a single category, designated $\mathrm{Gm}(\mathrm{b})$, for notational convenience.

Six unambiguous haplotypes were apparent in these data. Four of the haplotypes, a;g, $a ; b, f a ; b$, and ax;g, are common in New Guinea (Curtain et al., 1971, 1972; Steinberg et al., 1972; Steinberg and Larrick, 1981) but the fifth and sixth haplotypes are unusual. The $a ; b c^{3,5}$ haplotype, represented by a single copy in this sample, is most often found in African blacks (Giblett, 1969), and a Gm(c)positive haplotype has not been previously discovered in New Guinea (Giles et al., 1965; Curtain et al., 1971, 1972; Schanfield, 1971; Steinberg et al., 1972; Steinberg and Larrick, 1981). Another unique finding in this sample is that eight out of 513 individuals are $\mathrm{Gm}(\mathrm{a})$ positive and negative for all other specificities. This suggests a haplotype, a; -, with a frequency of about 0.12 . This haplotype has never been observed in other highland populations (Curtain et al., 1972; Steinberg et al., 1972) or in other Melanesians (Curtain, 1974). It should be noted that this haplotype is recessive in combination with any other $\mathrm{Gm}$ (a)positive haplotype; consequently, it could easily be undetected, even if present at polymorphic frequencies.

\section{Red cell enzymes}

A number of rare variants and private polymorphisms occur within the Gainj and Kalam. These are defined as apparently unique alleles that occur within a single or several related tribes. The rare variant category applies to those alleles below an arbitrarily set threshold frequency (say 1 or $2 \%$ ), while private polymorphisms are those alleles with frequencies above the threshold level (Neel, 1978).

Four rare variants were encountered. Two individuals were heterozygous for an NP variant similar but probably not identical to the type 4 variant of Edwards (1971). It is designated as the NP 4-Kalam variant here. Six individuals were heterozygous at the ADA locus, with the variant being identified as ADA 6-Kalam because of the apparent similarity to the type- 6 variant of Radam et al. (1974). A single individual had a PEPA variant (3-Kalam), electrophoretically similar to the type-3 variant of Lewis and Harris (1967). Three individuals were heterozygous for an FUM variant (2-Kalam), which appears similar to the type-2 variant of Edwards and Hopkinson (1978). A direct comparison of the electrophoretic mobility of these variants with the appropriate reference sample could not be completed, but it is reasonable to assume that they are not identical to similar variants observed in European populations.

Only the rare variants observed in the University of Michigan laboratories are presented in the above discussion and used in our subsequent estimates of heterozygosity. We have restricted our discussion and analysis to the 1983 sample for the purposes of uniformity of technique and sample size. Had we included the 1978 collection, four more rare variants, GPT ${ }^{6}, \mathrm{PGD}^{\text {Wantoat }}, \mathrm{PGK}^{4}$, and $\mathrm{MDH}^{3}$, would have been listed. These variants are fairly widespread in Papua New Guinea and have served as the basis of indirect estimates of mutation rates (Bhatia et al., 1981).

Private polymorphisms have been discovered at two loci, GPI and PGM2. The vari- 
ants observed here are probably identical (although direct tests have not been made) to the GPI type-5 variant found in Oceanic peoples (Detter et al., 1968) and the $\mathrm{PGM}_{2}^{9}$ allele described by Blake and Omoto (1975).

Glucose-6-phosphate dehydrogenase (G6PD) is notable for its lack of variation in the study population. Throughout New Guinea, G6PD is the most common allele, but other highland and almost all coastal populations have G6PD deficiency types present at polymorphic levels (Curtain, 1974). In fact, G6PD deficiency is polymorphic, with $\mathrm{f}\left(\mathrm{G} 6 \mathrm{PD}^{-}\right)=$ 0.058 in the Simbai Valley Maring, a neighboring highland group with whom regular mate exchange occurs (Buchbinder and Clark, 1971). A priori, we would have expected to see G6PD deficiency in the Gainj and Kalam and, possibly, differences between the low-lying Ramu Valley and the highland Takwi and Asai Valleys. Thus, in relation to both the neighboring tribes and the distribution of malaria, the study population is somewhat enigmatic with respect to this locus.

\section{AVERAGE HETEROZYGOSITY}

The amount of genetic variation within a population is critical in the study of population genetics, because it limits all rates of evolutionary change and patterns of genetic differentiation (Hubby and Lewontin, 1966; Lewontin and Hubby, 1966). Investigations into genetic variability usually attempt to delineate the occurrence and relative frequencies, in well-defined populations, of variants at a sample of loci that have not been selected with respect to previously known levels of variation (Neel, 1978). It is universally agreed that electrophoretic variants of soluble proteins provide the best traits for quantifying such variation (cf. Harris and Hopkinson, 1972). The most popular measurements of variation are the proportion of loci with segregating alleles and the average per locus heterozygosity (Lewontin and Hubby, 1966). Both of these quantities have been observed to vary widely within and among species (Nei et al., 1976; Nevo, 1978).

A battery of 39 serum protein and red cell enzyme loci are routinely examined for the existence of electrophoretic variants in University of Michigan laboratories. These loci are indicated in Tables 2, 4, and 5. They represent proteins for which the biochemical properties are well understood and techniques of analysis are well developed. Since they are the basis of an ongoing mutation research project, they have not been selected with regard to previously known levels of variation. Thus, we believe these data are appropriate for estimating levels of heterozygosity. This is not to say that they are free of all the biases discussed by Harris and Hopkinson (1972) but only that they are reasonably free of the more obvious ones and are comparable with other published estimates.

Fourteen of the 39 loci (35.9\%) have variants segregating, and nine of these are polymorphic. We estimate average heterozygosity (as defined by Lewontin and Hubby [1966]) to be 0.053 . This level of heterozygosity is very close to the mean of 12 South American Indian tribes $(0.054)$ and lower than the respective Caucasian and Japanese means (0.078 and 0.077) (Harris and Hopkinson, 1972; Neel, 1978; Neel et al., 1978). It is tempting to interpret these data as reflecting differences in population structure between modern urban and tribal groups. This interpretation is plausible, but it deserves some scrutiny. The variance of our estimate, $V(h)$ $=0.014$, is high relative to its mean. While we do not know the exact sampling distribution of heterozygosity, theoretical and computer simulation studies (Nei and Roychoudhury, 1974; Nei et al., 1976) suggest that average heterozygosity estimates are quite sensitive to the number of loci employed. Reviewing the numbers of loci used to obtain the four heterozygosity estimates presented here, we find them to be 78 (Caucasian), 25 (Japanese), 39 (New Guinea), and about 28 (Amerindian, varying with tribe). If we restrict ourselves to the loci investigated by Neel (1978) for South American Indian tribes, we find that the estimated heterozygosity for the Gainj and Kalam rises to about 0.060 . We also recall that the original heterozygosity estimate presented for Caucasians by Hopkinson and Harris (1971), based on only 28 loci, was 0.055 . Thus, when we maximized comparability of heterozygosity estimates for the different groups, we obtain the values 0.077 (Japanese), 0.060 (New Guinea), 0.055 (Caucasians), and 0.054 (Amerindians), and the distinction between tribal and modern urban populations disappears.

Thus, while there may be a difference in levels of heterozygosity between human populations at different levels of acculturation, current information does not lead to an unambiguous conclusion. We might expect populations to have lower levels of heterozygosity because of such factors as the presence of local subdivisions, isolation by distance, and small effective sizes. On the other hand, levels of heterozygosity may be quite resilient 
to the ecological and cultural diversity within the human species. If this is true, the vast store of cultural variation affecting human mating structure would amount to little more than a collection of subtle nuances with relatively minor effects on this genetic characteristic of the species.

\section{CONCLUSIONS}

The Gainj- and Kalam-speaking peoples of Papua New Guinea have now been studied by our group for almost a decade and on two separate field expeditions. These efforts have produced a wealth of anthropological data. The data analyses and summaries presented here are a first step toward our long-term goal of understanding the relationship between tribal genetic structure and the social, demographic, and ecological factors that underlie it.

Although these tribal peoples have become increasingly acculturated since initial contact 30 years ago, much of their precontact life-style has been retained, and the settlement pattern and demographic profile have been relatively stable. The population size appears to be near a stable equilibrium, and the number of population subdivisions seems similarly balanced (Wood, 1980; Wood and Smouse, 1982). Additionally, both the traditional system of marriage and the extreme geographic restriction of population movement persist.

The Gainj and Kalam generally exhibit genetic features typical of other New Guinea highland populations, but they also exhibit some distinguishing characteristics. The polymorphic level of $\mathrm{Ge}\left(\mathrm{a}^{-}\right)$distinguishes them from other highland populations, and the Fyb allele and the $\mathrm{Gm}\left(\mathrm{a} ; \mathrm{bc}^{3,5}\right)$ haplotype, while usually absent in Melanesia, are present among the Gainj and Kalam. Four rare variants, NP (4-Kalam), ADA (6-Kalam), PEPA (3-Kalam), and FUM (2-Kalam), have been discovered. Whether these rare variants are unique to this group or not remains to be seen because neighboring populations have not been typed at these loci.

The best estimate of average per locus heterozygosity is seen to be close to the level observed in South American Indian tribes and somewhat less than urban Caucasians or Japanese. These results may be caused by differences in population structures of modern urban and tribal societies, but the statistical significance of this reduction in heterozygosity is questionable. Regardless of this issue, we can safely conclude that the ob- served level of heterozygosity provides ample opportunity for the evolution of genetic infrastructure within the Gainj and Kalam. With this in mind, the problems of deviations from panmictic equilibrium, pairwise relationships between parishes, migration, drift, and so forth will be addressed in subsequent articles.

\section{ACKNOWLEDGMENTS}

Fieldwork with the Gainj and Kalam populations depended on the help of many people. We are indebted to Drs. Michael Alpers and Peter Heywood for the logistic support of, and affiliation with, the Papua New Guinea Institute of Medical Research. A special note of gratitude is extended to Carol and Travis Jenkins for their friendship and accommodations during the course of the fieldwork. Finally, the tremendous patience and cooperation of the Gainj- and Kalamspeaking peoples has made this study possible.

We thank Drs. George Estrabrook, Frank Livingstone, Nicholas Martin, James V. Neel, and Paula Nemeth for their comments on earlier drafts of this article. Financial support of this research was partially provided by National Institutes of Health grants, NIH R01 GM30135, and NIH T32 GM07544, Department of Energy Contract Number AC02-82ER60089, and a Dissertation grant from the Horace H. Rackham School of Graduate Studies, University of Michigan.

\section{LITERATURE CITED}

Barrantes R, Smouse, PE, Neel, JV, Mohrenweiser, HW, and Gershowitz, $H$ (1982) Migration and genetic infrastructure of the Central American Guaymi and their affinities with other tribal groups. Am. J. Phys. Anthropol. 58:201-215.

Bhatia, KK, Blake, NM, Serjeantson, SW, and Kirk, RL (1981) Frequency of private electrophoretic variants and indirect estimates of mutation rate in Papua New Guinea. Am. J. Hum. Genet. 33:112-122.

Blake, NM (1976) Glutamic pyruvic transaminase and esterases D types in the Asian-Pacific area. Hum. Genet. 35:91-102.

Blake, NM (1978) Malate dehydrogenase types in the Asian Pacific area, and a description of new phenotypes. Hum. Genet. 43:69-80.

Blake, NM, and Omoto, K (1975) Phosphoglucomutase types in the Asian-Pacific area: A critical review including new phenotypes. Ann. Hum. Genet. 38:251273.

Bodmer, WF, Cavalli-Sforza, LL (1968) A migration model for the study of random genetic drift. Genetics 59:565-592.

Booth, PB, McLoughlin, K, Hornabrook, RW, and Macgregor, A (1971a) The Gerbich blood group system in New Guinea. III. The Madang district, the highlands, and the south Papuan coast. Hum. Biol. Oceania 1:267272. 
Booth, PB, McLoughlin K, Hornabrook, RW, Macgregor, A, and Malcolm LA (1971b) The Gerbich blood group system in New Guinea. II. The Morobe district and north Papuan coast. Hum. Biol. Oceania 1:259-266.

Booth, PB, Wark, L, McLoughlin, K, and Spark, R (1971c) The Gerbich blood group system in New Guinea. I. The Sepik district. Hum. Biol. Oceania 1:215-222.

Brewer, GJ (1967) Achromatic regions of tetrazolium stained starch gels: Inherited electrophoretic variation. Am. J. Hum. Genet. 19:674-685.

Brown P (1978) Highland Peoples of New Guinea. Cambridge: Cambridge University Press.

Buchbinder, G (1973) Maring Microadaptation: A Study of Demographic, Nutritional, Genetic and Phenotypic Variation in a Highland New Guinea Population. Ph.D. Dissertation. Columbia University, New York. University Microfilm, Ann Arbor, Michigan.

Buchbinder, G, and Clark, P (1971) The Maring people of the Bismark ranges of New Guinea. Hum. Biol. Oceania. 1:121-133.

Curtain, CC (1974) Blood protein markers in Melanesia. Yearbook Phys. Anthropol. 18:246-284.

Curtain, CC, van Loghem, E, Baumgarten, A, Golab, T, Gorman, J, Rutgers, CF, and Kidson, C (1971) The ethnological significance of the gamma-globulin (Gm) factors in Melanesia. Am. J. Phys. Anthropol. 34:257272.

Curtain, CC, van Loghem, E, Fundenberg, HH, Tincale, NB, Simmons, RT, Doherty, RL, and Vos, G (1972) Distribution of the immunoglobulin markers at the IgG1, IgG2, IgG3, IgA2, and k-chain loci in Australian aborigines: Comparison with New Guinea populations. Am. J. Hum. Genet. 24:145-155.

Detter, JC, Ways, PO, Giblett, ER, Baughan, MA, Hopkinson, DA, Povey, S, and Harris, H (1968) Inherited variations in human phosphohexose isomerase. Ann. Hum. Genet. 31:329-338.

Edwards, YH, Hopkinson, DA, and Harris, H (1971) Inherited variants of human nucleoside phosphorylase. Ann. Hum. Genet. 34:395-408.

Edwards, YH, and Hopkinson, DA (1978) The genetic determination of fumarase isozymes in human tissues. Ann. Hum. Genet. 42:303-314.

Ford, E (1974) Climate. In E Ford (ed): Papua New Guinea Resource Atlas. Melbourne: Jacaranda.

Friedlaender, JS, and Steinberg, AG (1970) Anthropological significance of gamma globulin (Gm and Inv) antigens in Bougainville Island, Melanesia. Nature 228:59-61.

Gajdusek, DC, and Alpers, M (1972) Genetic studies in relation to kuru. Am. J. Hum. Genet. 24:S1-38.

Gershowitz, H, Layrisse, M, Layrisse, Z, Neel, JV, Chagnon, NA, and Ayres, M (1972) The genetic structure of a tribal population, the Yanomama Indians. II. Eleven blood group systems and the ABH-Le secretor traits. Ann. Hum. Genet. 35:261-269.

Gershowitz, H, and Neel, JV (1978) The immunoglobin allotypes $(\mathrm{Gm}$ and $\mathrm{Km}$ ) of twelve Indian tribes of Central and South America. Am. J. Phys. Anthropol. 49:289-301.

Giblett, ER (1969) Genetic Markers in Human Blood. Oxford: Blackwell Scientific Publications.

Giles, E, Ogan, E, and Steinberg, AG (1965) Gammaglobulin factors (Gm and Inv) in New Guinea: Anthropological significance. Science 150:1158-1160.

Greenbaum, BW, Crim, M, and Zojan, PJ (1977) Rapid phenotyping of the group specific component by immunofixation on cellulose acetate. J. Forensic Sci. 22:586-589.

Harris, H, and Hopkinson, DA (1972) Average heterozy- gosity per locus in man: an estimate based on the incidence of enzyme polymorphism. Ann. Hum. Genet. (Lond) 36:9-20.

Hogbin, I, and Wedgwood, C (1952) Local grouping in Melanesia. Oceania 23:241-276.

Hopkinson, DA, and Harris, H (1971) Recent work on isozymes in man. Annu. Rev. Genet. 5:5-32.

Howells, WW (1973) The Pacific Islanders. New York: Charles Scribner's Sons.

Hubby, JL, and Lewontin, RC (1966) A molecular approach to the study of genic heterozygosity in natural populations. I. The number of alleles at different loci in Drosophila pseudoobscura. Genetics 54:577-594.

Johnson, PL (1981) When dying is better than living: Female suicide among the Gainj of Papua New Guinea. Ethnology 20:325-334.

Johnson, PL (1982) Gainj Kinship and Social Organization. Doctoral Dissertation. University of Michigan, Ann Arbor.

Kirk, RL, McDermid, EM, Blake, NM, Wright, RL, Yap, $\mathrm{EH}$, and Simmons, MJ (1973) The distribution of red cell enzyme and serum protein groups in a population of Dani (Pit River, West Irian). Hum. Genet. 17:345350.

Kitchin, FD, Bearn, AG, Alpers, M, and Gajdusek, DC (1972) Genetic studies in relation to kuru. III. Distribution of the inherited serum group-specific protein (Gc) phenotypes in New Guineans: An association of kuru and the Gc Ab phenotype. Am. J. Hum. Genet. 24:S72-S85.

Lewis, WHP, and Harris, H (1967) Human red cell peptidases. Nature, 215:251-314.

Lewontin, RC, and Hubby, JL (1966) A molecular approach to the study of genic heterozygosity in natural populations. II. Amount of variation and degree of heterozygosity in natural populations of Drosophila pseudoobscura. Genetics 54:595-609.

$\mathrm{Li}, \mathrm{CC}$ (1956) The components of sampling variance of ABO gene frequency estimates. Am. J. Hum. Genet. 8:133-137.

Li, CC (1976) Population Genetics. Pacific Grove, CA: Boxwood, Ch. 6 .

Majnep, IS, and Bulmer, RNH (1977) Birds of My Native Kalam Country. London: Oxford University Press.

Malcolm, LA (1970) The eruption time of permanent teeth and determination of age in New Guinea. Trop. Geog. Med. 22:401-406.

Malcolm, LA, Booth, PB, and Cavalli-Sforza, LL (1971) Intermarriage patterns and blood group gene frequencies of the Bundi people of the New Guinea highlands. Hum. Biol. 43:187-199.

Maurer, HR, and Allen, RCL (1972) Useful buffer and gel systems for polyacrylamide gel electrophoresis. 2 . Klin. Chem. Klin. Biochem. 10:220-225.

Morton, NE (1969) Human population structure. Ann. Rev. Genet. 3:53-74.

Neel, JV (1978) Rare variants, private polymorphisms, and locus heterozygosity in Amerindian populations. Am. J. Hum. Genet. 30:465-490.

Neel, JV, Gershowitz, H, Mohrenweiser, HW, Amos, B, Kostyu, DD, Salzano, FM, Mestriner, MA, Lawerence, D, Simoes, AL, Smouse, PE, Olivier, WJ, Spielman, RS, and Neel, JV, Jr (1980) Genetic studies on the Ticuna, an enigmatic tribe of Central Amazonas. Ann. Hum. Genet. 44:37-54.

Neel JV, Tanis, RJ, Migliazza, EC, Spielman, RS, Salzano, FM, Olivier, WJ, Morrow, M, and Bachofer, S (1977) Genetic studies of the Machusi and Wapishang Indians. I. Rare genetic variants and a "private polymorphism" of esterase. Ann. Hum. Genet. 36:81-107. 
Neel, JV, Ueda, N, Satoh, C, Ferrell, RE, Tanis, RJ, and Hamilton HB (1978) The frequency in Japanese of genetic variants of 22 proteins. V. Summary and comparison with data on Caucasians from the British Isles. Ann. Hum. Genet. 41:429-441.

Nei, M, Fuerst, PA, and Chakraborty, F (1976) Testing the neutral mutation hypothesis by distribution of single locus heterozygosity. Nature 262:491-493.

Nei, M, and Roychoudhury, AK (1974) Sampling variances of heterozygosity and genetic distance. Genetics 76:379-390.

Nevo, E (1978) Genetic variation in natural populations: Patterns and theory. Theor. Popul. Biol. 13:121-177.

Omoto, K, and Blake, NM (1972) Distribution of genetic variants of erythrocyte phosphoglycerate kinase (PGK) and phosphohexose isomerase (PHI) among some population groups in southeast Asia and Oceania. Ann. Hum. Genet. 36:61-67.

Paijmans, K (1976) Vegetation. In K Paijmans (ed): New Guinea Vegetation. Canberra: Australian National University.

Radam, G, Strauch, H, and Prokop, O (1974) En seltener Phanotyp im Adenosindesaminase polymorphismus: Hinweis auf die existenz eines neven allels. Humangenetik 25:247-250.

Rappaport, RA (1968) Pigs for the Ancestors: Ritual in the Ecology of a New Guinea People. New Haven, CT: Yale University Press.

Schanfield, MS (1971) Population Studies of Gm and Inv Antigens in Asia and Oceania. Ph.D. Dissertation. University of Michigan, Ann Arbor. University Microfilm, Ann Arbor.

Simmons, RT, and Booth, PD (1971) A Compendium of Melanesia Genetic Data. Parkville, Victoria: Commonwealth Serum Laboratories, Vols. 1-4.

Simmons, RT, Graydon, JJ, Gajdusek, DC, Alpers, MP, and Hornabrook, RW (1972) Genetic studies in relation to kuru. II. Blood-group genetic patterns in kuru patients and populations of the eastern highlands of New Guinea, Am. J. Hum. Genet. 24:S39-S71.

Sinnett, P, Blake, N, Kirk, RL, Lai, LYC, and Walsh, RJ (1970) Blood, serum protein and enzyme groups among Enga-speaking people of the western highlands, New Guinea, with an estimate of genetic distance between clans. Archaeol. Phys. Anthropol. Oceania 5:236-252.

Smith, CAB (1969) Local fluctuations in gene frequencies. Ann. Hum. Genet. 32:251-260.

Sokal, RR, and Oden, NL (1978a) Spatial autocorrelation in biology. 1. Methodology. Biol. J. Linn. Soc. 10:199 228 .
Sokal, RR, and Oden, NL (1978b) Spatial autocorrelation in biology. 2. Some biological applications of evolutionary and ecological interest. Biol. J. Linn. Soc. 10:229249.

Steinberg, AG, Gajdusek, DC, and Alpers, M (1972) Genetic studies in relation to kuru. V. Distribution of human gamma globulin allotypes in New Guinea populations. Am. J. Hum. Genet. 24:S95-S110.

Steinberg, AG, and Larrick, JW (1981) Gm and Inv (Km) studies of Melanesian people on the Huon peninsula in northeast Papua New Guinea: Polymorphism for a GM $(1,5,10,11,13,14,17,21,26)$ haplotype. Am. J. Phys. Anthropol. 55:89-94.

Tanis, RJ, Neel, JV, Dovey, H, and Morrow, M (1973) The genetic structure of a tribal population, the Yanomama Indians. IX. Gene frequencies for 18 serum protein and erythrocyte systems in the Yanomama and five neighboring tribes. Nine new variants. Am. J. Hum. Genet. 25:655-676.

W.H.O. Committee on Human Immunoglobulin Allotype Markers (1976) Review of the notation for the allotypic and related markers of human immunoglobulins. J. Immunol. 117:1056-1058.

Weiner, JS, and Lourie, JA (1981) Practical Human Biology. New York: Academic Press.

Wood, JW (1980) Mechanisms of Demographic Equilibrium in a Small Human Population, the Gainj of Papua New Guinea. Ph.D. Dissertation. University of Michigan, Ann Arbor. University Microfilm, Ann Arbor.

Wood, JW Convergence of genetic distances in a migration matrix model. Am. J. Phys. Anthropol. (In press).

Wood, JW, Johnson, PL, Kirk, RL, McLoughlin, K, Blake, NM, and Matheson, FA (1982) The genetic demogra. phy of the Gainj of Papua New Guinea. I. Local differentiation of blood group, red cell enzyme and serum protein allele frequencies. Am. J. Phys. Anthropol. 57:15-25.

Wood, JW, and Smouse, PE (1982) A method of analyzing density-dependent vital rates with an application to the Gainj of Papua New Guinea. Am. J. Phys. Anthropol. 58:403-411.

Wood, JW, Smouse, PE, and Long, JC (1985) Sex-specific dispersal patterns in two human populations of highland New Guinea. Am. Naturalist 125:747-768.

Woodfield, DG, Scragg, RFR, Blake, NM, Kirk, RL, and McDermid, EM (1974) Distribution of blood, serum protein and enzyme groups among the Fuyuge speakers of Goilala sub-district. Hum. Hered. 24:507-519. 